\title{
Alternative futures for global biological invasions
}

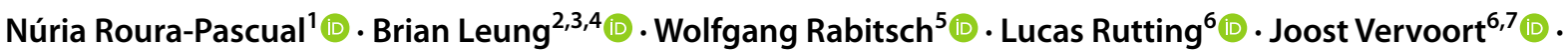 \\ Sven Bacher ${ }^{8}(1) \cdot$ Stefan Dullinger ${ }^{9}(1) \cdot$ Karl-Heinz Erb $^{10}$ (D) Jonathan M. Jeschke ${ }^{11,12,13}$ - Stelios Katsanevakis ${ }^{14}$ (1) \\ Ingolf Kühn ${ }^{15,16,17}$ - Bernd Lenzner ${ }^{18}$ (1) Andrew M. Liebhold ${ }^{19,20}$ (1) Michael Obersteiner ${ }^{21,7}$ (1)

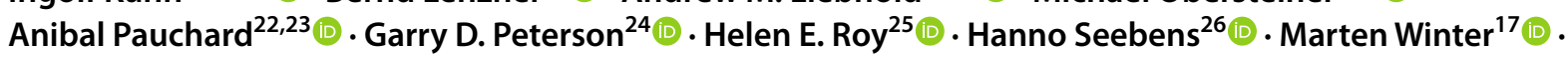

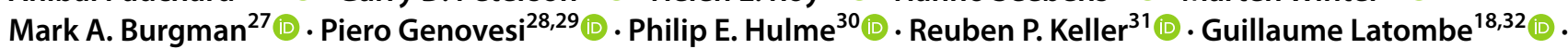 \\ Melodie A. McGeoch ${ }^{33}$ - Gregory M. Ruiz ${ }^{34}$ (D) Riccardo Scalera ${ }^{35}$ - Michael R. Springborn ${ }^{36}(\mathbb{D})$ \\ Betsy von $\mathrm{Holle}^{37}$ (D) Franz Essl ${ }^{18,38}$
}

Received: 5 May 2020 / Accepted: 16 April 2021 / Published online: 10 May 2021

(c) The Author(s) 2021, corrected publication 2021

\begin{abstract}
Scenario analysis has emerged as a key tool to analyze complex and uncertain future socio-ecological developments. However, currently existing global scenarios (narratives of how the world may develop) have neglected biological invasions, a major threat to biodiversity and the economy. Here, we use a novel participatory process to develop a diverse set of global biological invasion scenarios spanning a wide range of plausible global futures through to 2050 . We adapted the widely used "two axes" scenario analysis approach to develop four families of four scenarios each, resulting in 16 scenarios that were later clustered into four contrasting sets of futures. Our analysis highlights that socioeconomic developments and technological innovation have the potential to shape biological invasions, in addition to well-known drivers, such as climate and human land use change and global trade. Our scenarios partially align with the shared socioeconomic pathways created by the climate change research community. Several factors that drive differences in biological invasions were underrepresented in the shared socioeconomic pathways; in particular, the implementation of biosecurity policies. We argue that including factors related to public environmental awareness and technological and trade development in global scenarios and models is essential to adequately consider biological invasions in global environmental assessments and thereby obtain a more integrative picture of future social-ecological developments.
\end{abstract}

Keywords Alien species · Biodiversity models $\cdot$ Environmental scenarios $\cdot$ Future narratives $\cdot$ Global environmental change $\cdot$ Impacts $\cdot$ Management

\section{Introduction}

Biological invasions are recognized as a major driver of biodiversity loss (Pyšek et al. 2020). Invasive alien species (IAS) can threaten native biota and alter ecosystem functioning, disrupt the delivery of ecosystem services and cause numerous social and economic impacts (Diagne et al. 2020; Simberloff et al. 2013). The number of alien species continues to increase globally with no sign of saturation despite

Handled by Iris C Bohnet, Czech University of Life Sciences Prague, Czech Republic.

Núria Roura-Pascual nrourapascual@gmail.com

Extended author information available on the last page of the article efforts to halt invasions (Seebens et al. 2017). Advances have been made in understanding the direct drivers of biological invasions, such as ecological determinants (Simberloff et al. 2013) and anthropogenic factors, including climate change (Hulme 2017), global trade (Early et al. 2015) and human disturbance (Spear et al. 2013). However, it is still unclear how these direct drivers are shaped by social developments and how indirect social drivers may determine the future influence of biological invasions (e.g. Lotz and Allen 2013). A better understanding of how social change may determine biological changes is a prerequisite to understand and effectively manage biological invasions in the Anthropocene (Essl et al. 2020).

Scenario analysis provides a systematic method to assess how complex interactions among many drivers of change 
may produce multiple plausible futures (Peterson et al. 2003). Scenario analysis has been increasingly used to analyze likely outcomes of global and regional environmental developments (Oteros-Rozas et al. 2015; Pereira et al. 2020; Spangenberg et al. 2012; van Vuuren et al. 2014). Scenarios are neither predictions nor forecasts, rather they are descriptions and/or qualitative explorations of alternative paths along which the future might unfold (Van der Heijden 2005). The comparative analysis of a set of scenarios can be used to identify key uncertainties and allows the incorporation of alternative or competing perspectives and theories into analysis of potential futures (Peterson et al. 2003). Scenarios are qualitative in nature, although they can be combined with models to produce quantitative estimates of future changes (Lenzner et al. 2019).

We used scenario analysis to investigate the complex and uncertain interactions underlying biological invasions and to capture a variety of expert knowledge on how biological invasions interact with other relevant drivers of global change. The development of scenarios allowed us to explore a wide range of potential variations in the number of IAS that are likely to become established through to 2050 . Although analyses of biological invasions have been undertaken at regional scales (e.g. Chytrý et al. 2012; Le Maitre et al. 2004; Roura-Pascual et al. 2011; Wilson et al. 2020), the last global scenario analyses incorporating biological invasions were completed over two decades ago (Carpenter et al. 2005; Sala et al. 2000) and focused on drivers of biodiversity change rather than invasions themselves. Therefore, undertaking an analysis of global trajectories of biological invasions both addresses a critical research gap in environmental science (IPBES 2019), by developing a set of global IAS scenarios and linking those to existing global scenarios. Furthermore, these scenarios can contribute to the ongoing Intergovernmental Science Policy Platform on Biodiversity and Ecosystem Services (IPBES) assessment of Invasive and Alien Species (Stoett et al. 2019), as well as provide a starting point for future quantifications of the effects of biological invasions on the environment and human livelihoods (Lenzner et al. 2019).

We developed new global scenarios for biological invasions to avoid being constrained by pre-existing scenarios that were not created with a focus on the drivers of IAS change, such as the widely used Shared Socioeconomic Pathways (SSPs). The SSPs scenarios were developed by the climate change research community and include both qualitative descriptions and quantifications of broad trends in socioeconomic developments (van Vuuren et al. 2014). These scenarios are used to produce alternative sets of future drivers for integrated assessment models simulating the evolution of land use, energy consumption and resulting greenhouse gas emissions under different climate policy assumptions (O'Neill et al. 2017). However, the development of these scenarios has primarily focused on climate change and they only offer one set of scenarios, framed by a specific set of assumptions, excluding many other framings of potential futures. We compared the SSPs against our biological invasion scenarios, to advance the integration of invasion science into global environmental assessments, a topic that has been identified as a research priority (CBD 2010; IPBES 2019).

\section{Methods}

\section{Scenarios development}

We adapted the common "two axes" scenario analysis approach (Van der Heijden 2005). Although the two-axes scenario approach has strong benefits in its ability to communicate a set of scenarios quickly and in a transparent manner, the use of a single set of scenarios framed through this approach has been criticized, because it limits the exploration of futures through a single set of assumptions and drivers (Vervoort et al. 2015). There are alternative methods that integrate many drivers in a single scenario set, but such approaches end up with a limited set of plausible futures and run the risk of being less transparent in their assumptions (Lord et al. 2016).

Our approach was to construct multiple two-axis scenario sets, i.e. four families of four scenarios each. This approach allowed us to investigate potential futures through multiple framings based on the different driver combinations. This, in turn, enabled us to explore a much more multidimensional possibility space for plausible trajectories of biological invasions. We then clustered the 16 scenarios we had developed into a reduced and manageable set of futures (representing archetypes of scenarios) to facilitate comparisons with the single set of widely used SSPs (Fig. 1).

The scenario analysis was conducted using a six-step participatory process, combining expert-based online discussions with a two-day workshop (Vienna, 6-7 October 2016) (Fig. 1). The participants were mainly invasion biologists (24 out of 30), but four experts on topically relevant research such as global change biology and environmental economics and two experts on scenario development were also present (Table S1). Attendees to the workshop (19) were mainly from Europe, but there were also three non-European experts. The remaining participants that contributed online before and after the workshop were four European and seven international collaborators (Table S1). All participants are authors of the manuscript.

Step 1. Specify objective. All participants (30) agreed upon the objective of the scenario analysis through online discussions, which was: "Exploring different plausible futures concerning biological invasions at the global level through to 2050". Multiple indicators are available to assess 


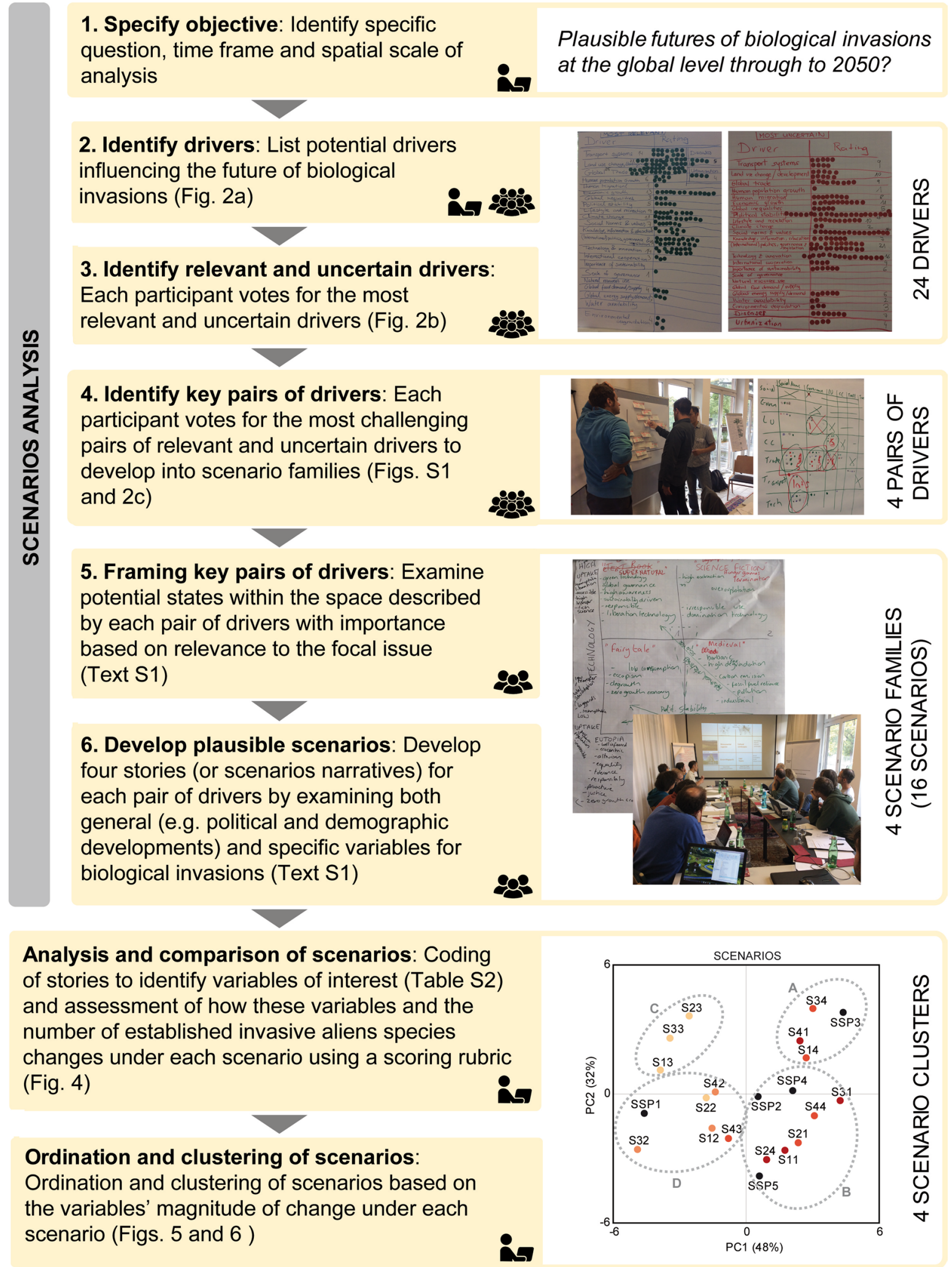

Fig. 1 Flow chart and photographs showing methodologies used to develop global scenarios for biological invasions through to 2050 . The icons indicate the type of activity and the people involved in each step (2: online contributions of all participants, workshop participants, contributions of breakout groups) 
the status of biological invasions (Wilson et al. 2018), but participants used the number of established IAS as the most relevant indicator when thinking about the future. It was preferred over other indices (i.e. rate of change or IAS impact) because of its simplicity and direct link with drivers influencing invasions.

Step 2. Identify drivers. Scenario development experts (L. Rutting and J. Vervoort) reviewed a wide range of existing scenario exercises (Alexandratos and Bruinsma 2012; CCAFS 2014; Gallopin et al. 1997; IPCC 2000, 2013; Mora et al. 2016; OECD 2009; Palazzo et al. 2016; Rockefeller Foundation and GBN 2010; Vervoort et al. 2016; Vervoort et al. 2013) and identified the drivers considered in these future scenarios. This preliminary list of drivers was refined by all participants prior to the workshop and also during the scenario workshop. During this process participants modified, added and removed drivers based on the published literature and their expertise to create a set of drivers influencing biological invasions through to 2050 .

Step 3. Identify relevant and uncertain drivers. Participants at the workshop selected the most relevant (i.e. important for biological invasions) and uncertain drivers (i.e. the range of plausible different directions this driver may take is largely unknown) from the list drawn in the previous step based on a voting system. Each participant had ten points to use to rank the most relevant drivers influencing the future status of biological invasions and an additional ten points to rank the most uncertain drivers based on their expertise. Scores were distributed freely among the drivers, with the possibility of assigning multiple points to a single driver. The drivers were then plotted in a coordinate system on the basis of their relevance and uncertainty. Workshop participants examined the position of each driver in the coordinate system and selected through group discussion the highest ranking drivers.

Step 4. Identify key pairs of drivers. This step involved the selection of pairs of drivers that led to the most challenging, diverse and relevant scenarios for exploring the future of biological invasions. Instead of choosing one single pair of drivers (Van der Heijden 2005) or combining a larger number of drivers (Lord et al. 2016) into one overarching, small set of scenarios, workshop participants discussed and voted on the most useful (i.e. challenging, diverse and relevant) pairs of two drivers. First, participants voted for all possible pairs of drivers retained in the previous step and identified the pairs with the most votes, and then voted and selected the four most useful pairs among those with the most votes obtained in the previous voting round. In each voting round, each participant at the workshop had five points to distribute freely among the pairs of drivers; it was possible to assign multiple points to a single pair or to leave some points unassigned. These four pairs of drivers were developed into four scenario families (composed of four scenarios each) and each pair of drivers determined the framing of each future in the family in the following steps.

Step 5. Framing key pairs of drivers. Examination and framing of each of these four pairs of drivers was carried out by breakout groups composed of 4-5 workshop participants, who discussed the different possible states of the driver axes. Drivers can be conceptualized in different ways, for instance, economic development can be defined along extremes of high or low, stable or unstable, equal or unequal, etc. The participants in the workshop defined which driver states were most appropriate for exploring futures of biological invasions. They did so by examining combinations of driver states and what types of scenarios these combinations yield-if a combination did not yield a useful set of scenarios (i.e. challenging, diverse and relevant), then the participants redefined these driver states to produce a more useful set of scenarios.

Step 6. Develop plausible scenarios. Scenarios for biological invasions were developed by the same breakout groups that in the previous step examined and framed each pair of drivers. Each pair of drivers formed a pair of axes, which yielded four scenarios. The group developed narratives for these scenarios (i.e. descriptions of how the future may unfold under each scenarios), by examining both general, contextual developments (i.e. politics and demographic developments; socioeconomic and trade developments; lifestyle and values; technological developments; and environmental developments and natural resources) and specific details on biological invasions. It is important to note that while selected pairs of drivers served as starting points and a way to frame the scenarios, the other drivers from step 2, which did not define the scenario axes, could also be taken into consideration in the development of the scenario narratives themselves. Since each group worked on one pair of drivers, the workshop resulted in four families of four scenarios for a total of 16 different scenarios.

\section{Scenarios comparison}

To identify similarities and differences among the scenarios for biological invasion created during the scenario analysis, but also between these scenarios and the widely used SSPs, we clustered all scenarios based on a set of variables. To select these variables, first we coded the scenarios narratives by means of qualitative content analysis. We identified terms that symbolically captured the essence of the different portions of the narratives and organized them in categories (Saldaña 2013). These terms (hereafter referred to as variables) are affected by variations in scenario assumptions, but do not necessarily correspond to the drivers used to frame the scenarios. We identified variables that appeared in three or four families of scenarios and selected them as the variables of interest to compare the scenarios. 
Then, we qualitatively assessed how these variables of interest were likely to change under different scenarios for biological invasions by 2050 , as well as the resulting total number of established IAS. The assessment of these variables and the number of established IAS was standardized using a scoring rubric, where the magnitude of change was measured using a 5-level Likert scale ranging from +1 (high increase) to -1 (high decrease) (Table S3). A value of 0 (no change) designates the current rate of change, while "increase" implies an acceleration and "decrease" implies a slowing of the current rate of change. This scoring rubric was created by the study participants with the specific purpose to compare the scenarios. To facilitate the assessment and to ensure equivalencies among the different ratings, each level had a description associated with it. We attempted to link these descriptions to existing publications assessing and/or projecting changes in future trends related to each variable (i.e. publications embedded in Table S3); the use of absolute values did not intend to be exact, but served to characterize the magnitude of change of each variable and impacts across each five-level category (Table S3). Workshop participants were asked to assess only the scenarios that they contributed to create, by rating the variables considered in the scoring rubric based on the descriptions of the scenario narratives. This process was conducted online by the four breakout groups that created the scenarios during the workshop (in previous step 6). In addition to the scenarios for biological invasion, we conducted a similar assessment of the SSPs. The assessment of SSPs narratives based on the variables of interest considered in the scoring rubric was based on the scenario descriptions provided in several publications (Calvin et al. 2017; Dellink et al. 2017; Fujimori et al. 2017; Jiang and O'Neill 2017; Kriegler et al. 2017; O'Neill et al. 2017, 2016; Riahi et al. 2017; van der Mensbrugghe 2015; van Vuuren et al. 2017).

These expert-based assessments of future changes in variables of interest under the different scenarios were then used to ordinate and cluster the scenarios/variables. First we applied a principal component analysis (PCA) using the prcomp() function from the 'stats' package in R v4.0.3 (R Core Team 2020) and then used the first two components to visualize the distribution of scenarios in a bivariate plot formed by these two new linear variable combinations. Additionally, we also applied a hierarchical cluster analysis on the scenario and variable coordinates in the main two axes of the PCA. We used the hclust() function from the 'stats' package in R v4.0.3 (R Core Team 2020) and the complete linkage algorithm (the Ward algorithm gave similar results-not shown here). Scenarios for biological invasions were characterized by the number of established IAS expected to have become established by 2050 (i.e. last row in Table S3); this variable was not considered in the PCA, but it was used to differentiate scenarios likely to result in a low or high number of established IAS, respectively, and to assess the coherence of the scenarios within each cluster. These analyses enabled us to identify the relationships between the scenarios for biological invasions and those of SSP narratives, to ensure the consistency of our scenario narratives but also to contribute to the work of other research programs assessing the effects of global change on biodiversity.

\section{Results and discussion}

\section{Scenarios development}

The workshop participants identified 24 drivers as potentially suitable for building the scenarios for biological invasions, which were grouped into five categories: (1) politics and demography (6 drivers); (2) economy and trade (3 drivers); (3) lifestyle and values (4 drivers); (4) technology ( 2 drivers); and (5) environment and natural resources (9 drivers) (Fig. 2a). During the workshop, 10 of these 24 drivers were classified as being both relevant and uncertain for the storyline development (Fig. 2b). Although climate change (driver 16) was not among the most uncertain drivers, participants decided to include it in the scenario analysis because of its potential to exacerbate invasions (Hulme 2017). Other drivers presenting a high relevance and uncertainty were also combined into a single driver because of their strong relationships. For example, drivers related to the category lifestyle and values (i.e. drivers 11-13) were grouped together, and economic growth was merged with global trade (drivers 7 and 9, respectively). Seven drivers were finally considered as the most relevant and uncertain ones (Fig. 2b).

We evaluated all pairwise combinations of these seven drivers and used voting to select the four pairs of drivers to develop the scenarios. Among all possible pairs of drivers (i.e. 21 pairs), the four pairs considered the most diverging by the participants were: (1) international politics, governance and legislation vs. global trade; (2) global trade vs. social norms (composite of drivers 11-13); (3) social norms vs. technology and innovation; and (4) climate change vs. land use change/development (Figs. 2c and S1). These pairs of drivers included six unique drivers. These drivers correspond to well-known drivers of biological invasions, such as global trade, land use change/development and climate change, as well as drivers associated with societal variables (usually called indirect drivers, e.g. IPBES (2019)) that have been largely ignored in the invasion literature: international politics, governance and legislation; lifestyle and social norms; and technological development and innovations (Fig. 2c). The latter group of drivers could have an enormous influence on the number of IAS in the future, but they 


\section{a DRIVERS}

\begin{tabular}{|l|}
\hline POLITICS \& DEMOGRAPHY \\
\hline 1. Int. politics, governance and legislation \\
2. International cooperation \\
3. Political stability \\
4. Scale of governance \\
5. Human population growth \\
6. Human migration \\
\hline ECONOMY \& TRADE \\
\hline 7. Economic growth \\
8. Global inequalities \\
\hline 9. Global trade = \\
\hline LIFESTYLE \& VALUES \\
\hline 10. Importance of sustainability \\
\hline 11. Knowledge, information and education \\
12. Lifestyle and recreation \\
13. Social norms and values \\
\hline TECHNOLOGY \\
\hline 14. Technology and innovation \\
15. Transport systems \\
\hline ENVIRONMENT \& NATURAL RESOURCES \\
\hline 16. Climate change \\
\hline 17. Diseases \\
18. Environmental degradation \\
19. Global energy supply/demand \\
20. Global food demand/supply \\
21. Land use change/development \\
22. Natural resource use \\
23. Urbanisation \\
24. Water availability \\
\hline
\end{tabular}

Fig. 2 Socioecological drivers of biological invasions. a List of drivers grouped by categories, b rating based on the driver's relevance and uncertainty and $\mathbf{c}$ rating of selected set of driver pairs. Size of circles in $\mathbf{c}$ is proportional to the percentage of votes assigned to all driver pairs, while numbers in black circles indicate the percentage of votes given to the final set of driver pairs considered for scenario

are difficult to quantify. Each of these pairs of drivers was used to create a family of four scenarios (Fig. 3; Text S1).

\section{Scenarios comparison}

The sixteen scenarios for biological invasions identified using our novel multi-set scenario exploration span a wide range of futures, while also sharing similarities (Fig. 3; Text S1). Examining the scenarios narratives by means of qualitative content analysis, we found that the variables (i.e. terms of the content analysis) that received the highest attention across the different scenario families were those related to politics and demographic developments, as well as environmental and natural resources. Variables related to technological developments were the least assessed despite their potentially substantial impact on biological invasions (Table S2). Overall, we identified 17 variables of interest to assess the similarities/differences between scenarios using a scoring rubric developed for such purpose (Table S3).

\section{b RATING DRIVERS}

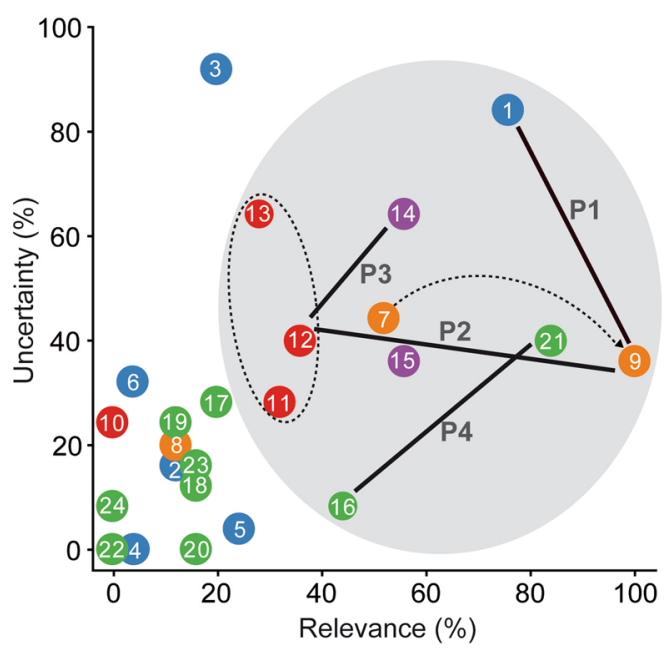

C RATING PAIRS OF DRIVERS

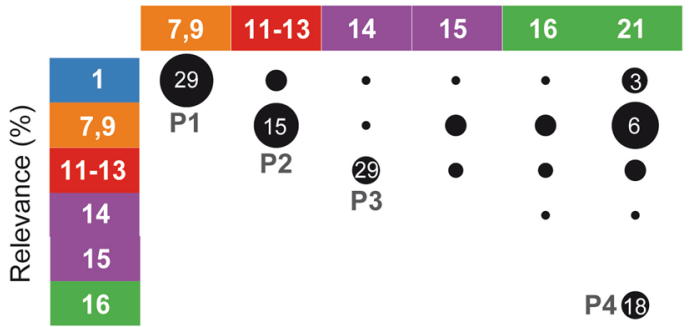

building. Drivers highlighted in bold in a indicate the most relevant and uncertain drivers according to $\mathbf{b}$. Dashed lines in $\mathbf{a}$ and $\mathbf{b}$ indicate drivers that were grouped together, while continuous lines join pairs of drivers used to develop scenarios for biological invasions (abbreviated as P1, P2, P3, P4)

The first two components of the PCA, based on the expert-based assessments of changes in these key variables (Fig. 4), explained $79 \%$ of the variance (Fig. 5). The first component (explaining $48 \%$ of variance) had positive associations with variables showing the impact of human activities on the environment and negative associations with variables related to political and social responsibility; hence, this component primarily measured public environmental awareness. The second component (32\% variance) had negative associations with variables related to technological and trade developments, so this component measured the implementation of technology and trade expansion worldwide (Fig. 5b). Scenarios were ordered along these two main axes and covered the entire scenarios' space (Fig. 5a).

Using the scenario coordinates in the main two axes of the PCA, we clustered the scenarios into four groups (representing the four corners of a scenarios' space) to have a manageable set of scenarios. These groups were coherent with respect to the level of biological invasions of the 

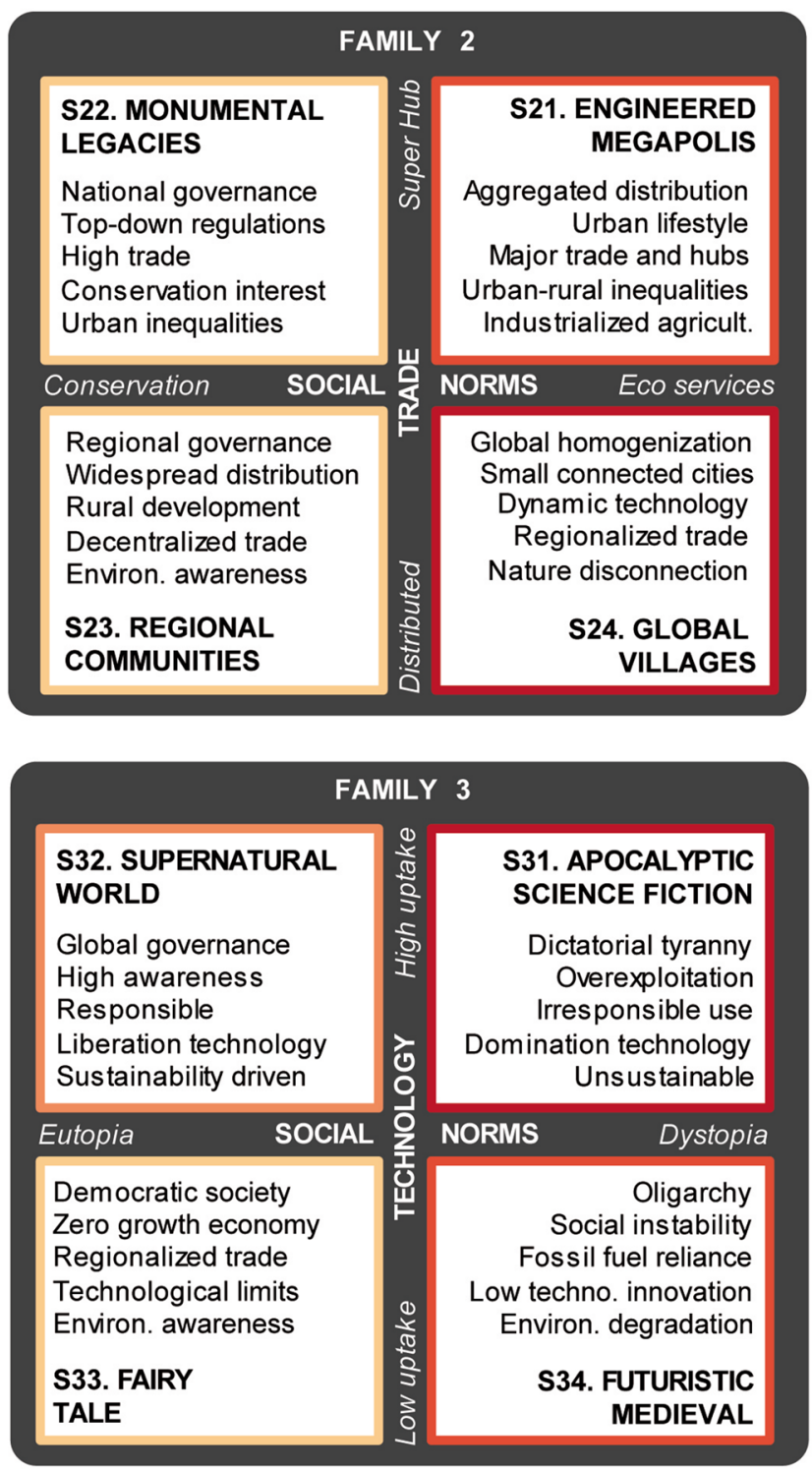

Fig. 3 Visual summary of scenarios for biological invasions grouped by scenarios families. Scenario families are composed of two axes, corresponding to the pairs of drivers selected for building the sce-

scenarios they included. Two groups corresponded to futures with higher level of biological invasions (A and B) and two others were characterized by lower levels of invasions (C and D) (Fig. 4, upper horizontal bar; Fig. 6). In addition to scenarios, we also clustered the variables based on how they co-varied across scenarios (Fig. 4, left vertical bar). Futures with rising numbers of established IAS were associated with increasing levels of human pressure on natural
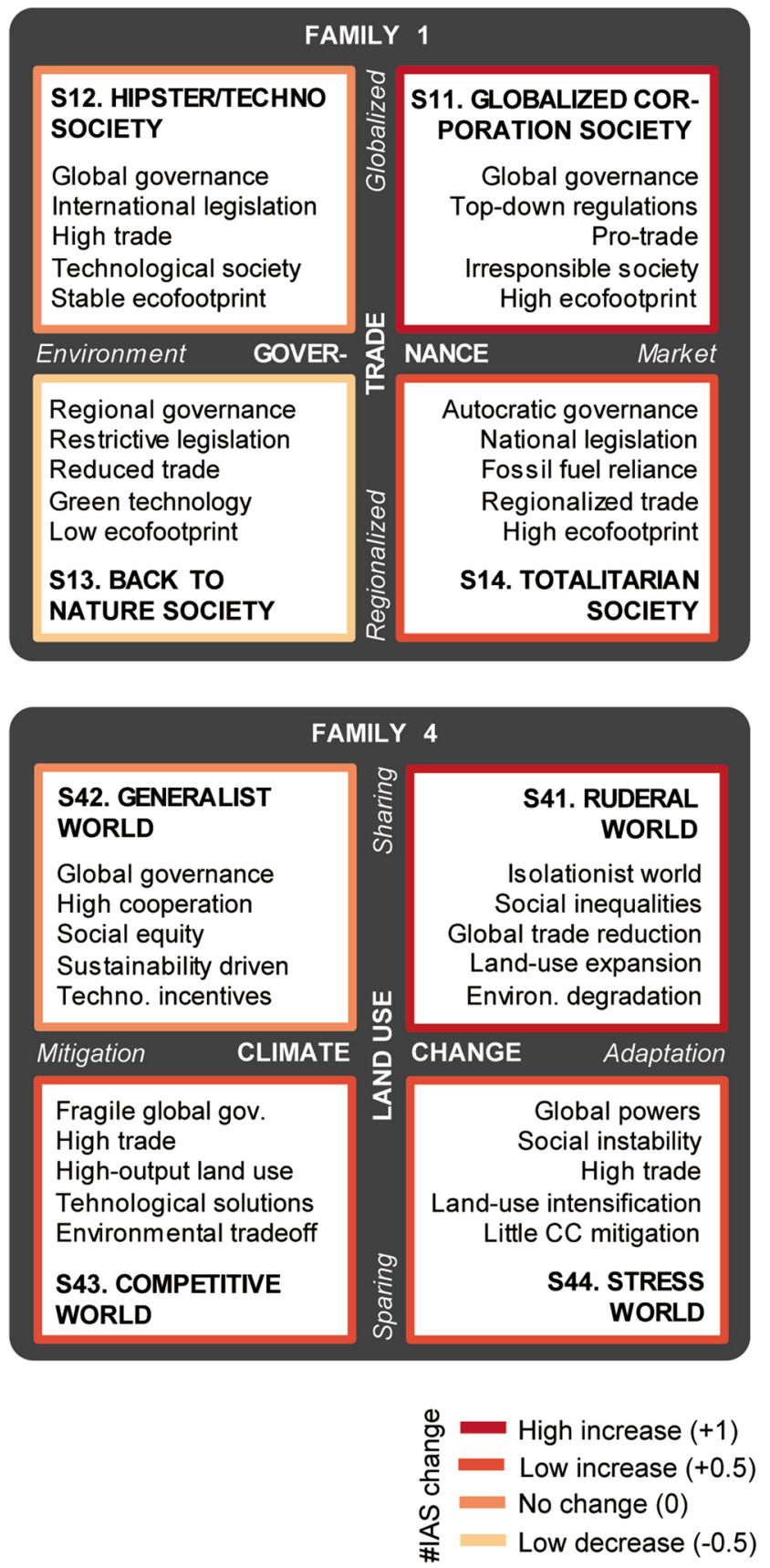

narios (Fig. 2b). Red shades correspond to expert-based assessments of changes in the number of established invasive alien species under each scenario (Fig. 4)

environments (cluster IV), while declining trends in biological invasions tended to occur in futures with increasing levels of sustainability policies and lifestyles (cluster I) and social and economic stability (cluster II). Increasing levels of global governance, technological development and transport (cluster III) were indistinctly associated with scenarios with both a high and low level of biological invasions (Fig. 4). Variables within the same cluster appeared highly correlated 


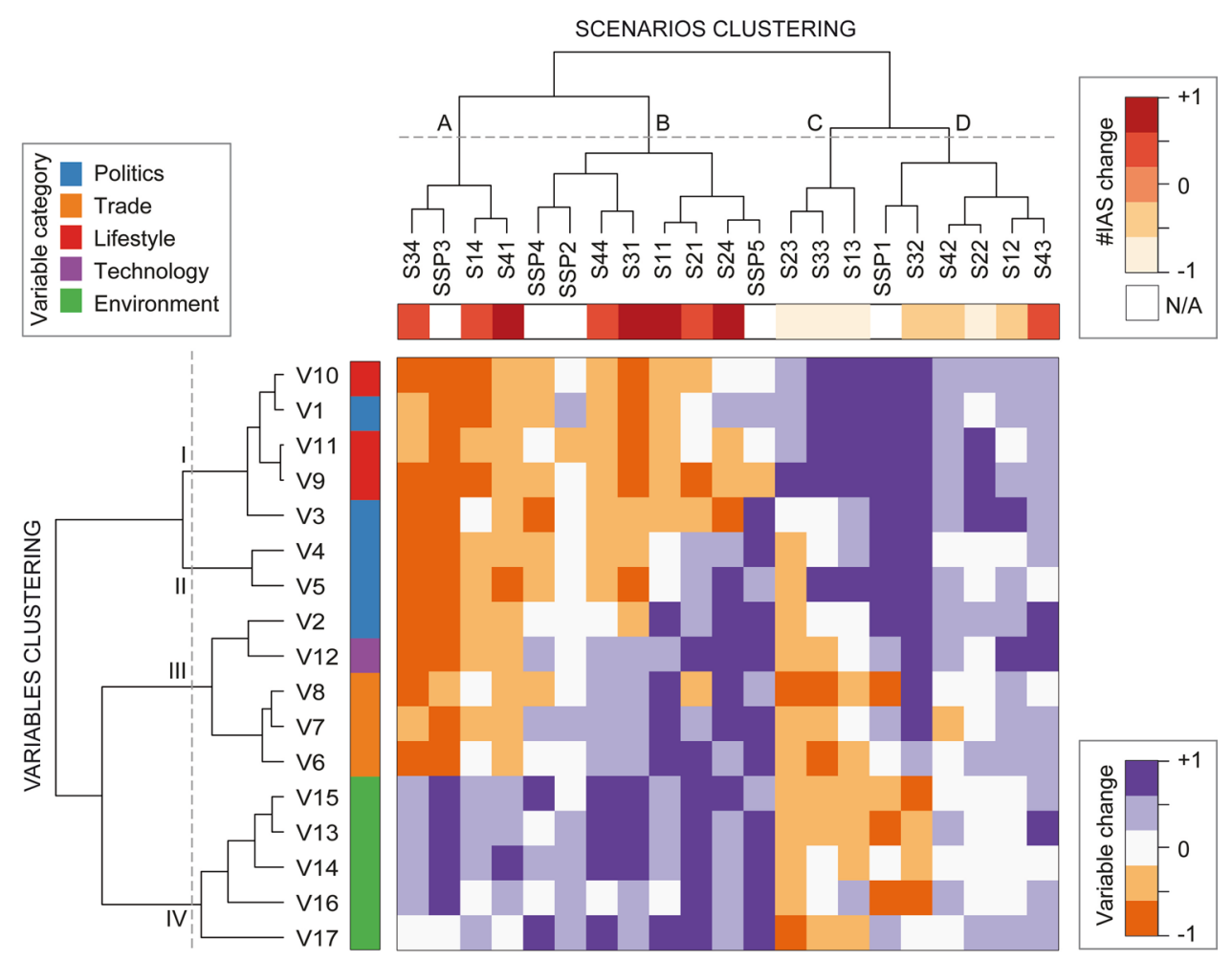

Fig. 4 Expert-based assessments of changes in socioecological variables of interest characterizing the 16 scenarios for biological invasions and five shared socioeconomic pathways (SSP; O'Neill et al. 2017) and clustering of scenarios/variables based on these changes. Orange blue shading intensity of the central matrix indicates the change in variables (in rows) under each scenario (in columns). The upper horizontal bar shows the change in the number of established invasive alien species, while the left vertical bar shows the five

(Fig. S2). These scenario/variable clusters are also evident from the PCA (Fig. 5).

Some of our results do not necessarily follow the common perception that biological invasions are only associated with increasing trade and economic growth, rather we found that how society develops (e.g. economic and social development, IAS mitigation strategies) is relevant to increase or reduce the risk posed by IAS. For example, the scenarios in cluster A present high levels of biological invasions despite declining trends in trade and transport (Fig. 6). Expert assessments suggest an increasing number of established IAS might also result from lack of global political and social coordination and a decline in sustainability policies and lifestyles, together with high levels of human modification of natural environments. Although recent analyses of biological invasions have incorporated surrogates of human modification and economic wealth, few analyses have included variables related to sustainability, such as levels of environmental awareness or development of sustainability policies (Sardain et al. 2019; Seebens et al. 2017). Our results suggest that understanding the future of broad categories into which the 17 variables are classified. Changes in variables and the number of established invasive alien species are described in a 5-level scale from -1 (high decrease) to +1 (high increase) (Table S3). Dendrograms represent the similarity of scenarios/variables based on the hierarchical cluster analysis. Variables (coded as V\#) are described in Table S3, while scenarios for biological invasions (S\#) in Text $\mathrm{S} 1$

biological invasions requires more interdisciplinary research that analyses how social and ecological drivers interact to shape biological invasions and in particular more attention should be paid to how emerging or novel technologies could reshape the introduction and spread of IAS (Kueffer 2017; Ricciardi et al. 2017).

\section{Comparison with shared socioeconomic pathways}

Following the development of our qualitative scenarios for biological invasions, we also used PCA and cluster analysis to compare them to the shared socioeconomic pathways (SSPs) (O'Neill et al. 2017). This comparison revealed clusters of similar scenarios from both sets of scenarios, but differences among SSPs did not always correspond to differences in IAS levels among our scenarios (Figs. 4 and 5a). Clusters A and B which have higher levels of biological invasions appear well represented by the SSPs. The scenarios in cluster A share features with the relatively pessimistic SSP3 (named Regional rivalry — a rocky road) in which the world disintegrates politically and economically into smaller 

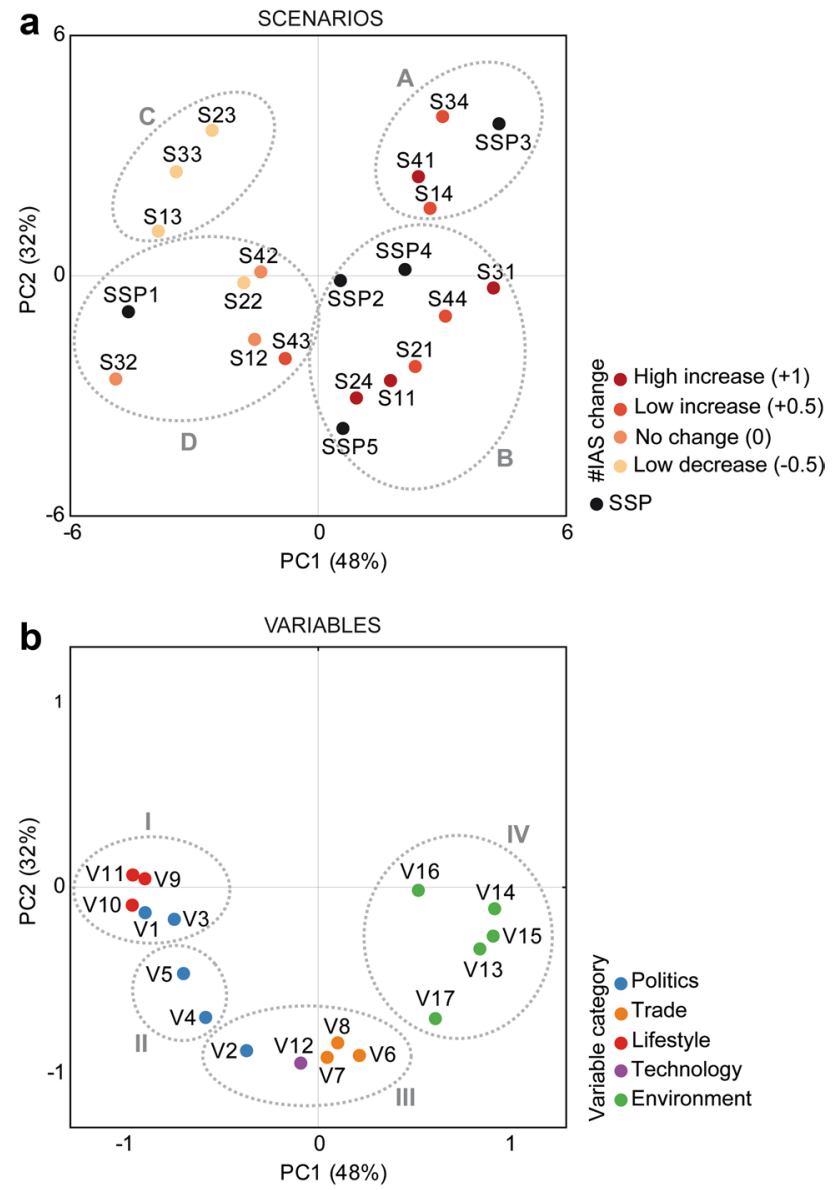

Fig. 5 Principal component analyses showing the relationships between scenarios for biological invasions and shared socioeconomic pathways (SSP; O'Neill et al. 2017). Graph (b) presents the correlations of the socioecological variables of interest used to characterize the scenarios (Fig. 4, central matrix) with the first two components of the principal component analysis. The dashed circles and letters/ roman numerals correspond to the clusters found in Fig. 4 for both scenarios and variables, respectively. The codes for variables (V\#) and scenarios for biological invasions (S\#) are listed in Table S3 and Text S1, respectively

regions, while most scenarios in cluster B would be more similar to the high economic growth pathway SSP5 (Fossilfueled development-taking the highway) reliant on very high levels of fossil fuel use (Figs. 4 and 5a). Two scenarios in cluster B (S31 and S44) would, however, share many elements with SSP4 (Inequality-a road divided) describing a highly unequal world and SSP2 (The middle-of-the-road) where trends do not shift markedly from historical patterns (Fig. 4). Although SSP2 is associated with cluster B, it is placed between clusters B and D (Fig. 5a).

Conversely, futures characterized by lower levels of IAS (C and D) are not well captured by the SSPs. The scenarios in cluster D are associated with the relatively optimistic SSP1 (Sustainability—taking the green road) that is oriented towards sustainability, but the IAS outcomes vary from low decrease (S22) to low increase (S43). While cluster D shares features with SSPs, scenarios in cluster C describing a world characterized by regional sustainable developments that present the lowest levels of biological invasions do not. Scenarios in this cluster could be similar to a SSP1 variant with rapid shift to lower consumption lifestyles (Figs. 4 and 5a).

The comparison of SSPs to our scenarios reveals that existing environmental scenarios do not represent key variables that shape biological invasions. The SSPs were created to represent different combinations of socioeconomic challenges for the mitigation and adaptation to climate change (O’Neill et al. 2017), but they lack influential biologically oriented variables responsible for major changes in future biodiversity. Some variables appear to co-vary with variables in the SSPs, but others, such as biosecurity, do not (Figs. 4 and 5). We suggest that including biological invasions in global environmental scenarios requires: (1) consideration of a broader range of sustainability oriented scenarios (such as those included in cluster $\mathrm{C}$ ) in order to capture a wider possible range of biological responses and (2) incorporation of key drivers/variables relevant for biological invasions that are currently missing from SSPs, such as how the geographic patterns of trade influences the spread of IAS and the implementation of biosecurity policies. Further understanding of these drivers/variables and their influence on other relevant variables is essential to enable quantitative analysis of how alternative future societal dynamics could shape biological invasions (Lenzner et al. 2019).

\section{Conclusions}

Ecological and a few economic factors have captured most of the attention of invasion science, but our expert-based analysis signals the primary role of socioeconomic developments and technological innovation as important drivers of biological invasions. Analyses of how trade and transport dynamics shape biological invasions have provided a starting point, but our study indicates that understanding the future of biological invasions requires analyzing how variables such as technological innovation, urbanization, wealth inequality, social stability, biosecurity and sustainability policies interact with one another to determine biological invasions. Realistic assessments of future biological invasions can only be achieved by examining a broader diversity of factors than are currently addressed and considering drivers and responses of biological invasions explicitly (rather than implicitly by relevant covariates).

Biological invasions are the result of interlinked and complex social-ecological dynamics, so further interdisciplinary research is required to broadly examine how people 


CLUSTER C
The scenarios Back to nature society (S13),
Regional communities (S23) and Fairy tale
(S33) are characterized by high levels of social
and environmental awareness, where policies
are implemented at a regional scale but
accommodate global environmental needs and
implications. Global trade is reduced, as are
the impacts of human activities on natural
resources. Environmental regulation is strong,
but its effectiveness weak given the
decentralized nature of public administration.
Scenarios in this cluster tend to be associated
with low levels of invasions due to decreased
globalization of trade and lower technology
developments.
CLUSTER A
3ิ The scenarios Totalitarian society (S14),
Futuristic medieval (S34) and Ruderal world (S41) are dominated by an irresponsible and inefficient use of natural resources, which does not respond to global mandates but to

乏 subjective and regional interests. Under these scenarios, there is high reliance on fossil fuels. There is also a deceleration in the rate of international trade, but it does not reduce climate change nor the introduction of alien species due to the lack of effective biosecurity. The resulting level of biological invasions is high or very high.
This cluster is characterized by the scenarios Hipster/Techno society (S12), Monumental legacies (S22), Generalist world (S42) and Competitive world (S43). There is a balanced regional and global governance system. The availability and utility of technology are high at a global scale, leading to an increase in global trade and solutions to mitigate the impact of some environmental pressures. Environmental challenges are taken seriously, and regulations are enforced. Scenarios in this cluster tend to be associated with medium levels of invasions because while global trade is elevated, effective biosecurity programs are widely implemented. An extreme case scenario is the Supernatural world (S32), a scenario representing a globally connected society where equality, justice and sustainability are highly valued and society's ecological footprint is significantly reduced.

\begin{tabular}{|c|}
\hline $\begin{array}{l}\text { CLUSTER B } \\
\text { This cluster includes the scenarios Globalized } \\
\text { corporation society (S11), Engineered } \\
\text { megapolis (S21) and Global Villages (S24). In } \\
\text { these scenarios, political agendas are driven } \\
\text { by global economic interests, often disregarding } \\
\text { most environmental needs. Productivity and } \\
\text { trade are high thanks to technological advances, } \\
\text { which are responsible for high consumption of } \\
\text { natural resources and fossil fuel reserves. An } \\
\text { urban life-style dominates. The level of } \\
\text { biological invasions is anticipated to be high or } \\
\text { very high due to intense globalization. A variant } \\
\text { of these scenarios would be scenarios } \\
\text { Apocalyptic science fiction (S31) and Stress } \\
\text { world (S44), which are characterized by lower } \\
\text { levels of international cooperation and an } \\
\text { unequal distribution of knowledge/technology } \\
\text { developments. }\end{array}$ \\
\hline
\end{tabular}

Fig. 6 Summary of clusters of scenarios for biological invasions derived from a hierarchical cluster analysis performed on expertbased assessments of changes in socioecological variables of interest under the 16 scenarios (Fig. 4). The description associated with each cluster has been elaborated based on the characteristics of the scenarios included in each group (Text S1). Red shades are proportional to the number of established invasive alien species expected for each cluster by 2050 and societies interact with biological invasions (Vaz et al. 2017). The expertise of workshop participants undoubtedly influenced the selection of factors explaining biological invasions. However, the diverse range of factors identified highlights the participants' breadth of expertise. Future scenario analyses would likely be improved if they were able to better represent the global variety of experiences surrounding biological invasions, for example by ensuring a diversity of experts with respect to age, gender, cultural background, education and expertise (Roy et al. 2020).

Our novel scenario development method has proven to be an important component in allowing us to engage with a multi-dimensional scenario space beyond any one scenario set, while our aggregation method allowed for a comparison across this larger set. We captured different potential future trajectories of biological invasions, focusing on a large variety of interacting drivers and then grouped these multiple scenarios into four clusters presenting divergent futures. Clusters can be considered as scenario archetypes that encapsulate the variability embedded within a certain future. Thus, they can be used as incipient or preliminary formulations to develop new global scenarios or to downscale global scenarios to finer spatial scales.

Further developments of these global scenarios and their refinement into regional or local contexts are needed to better understand the synergies between drivers/variables shaping the future of biological invasions across spatial scales. This work provides a first global analysis of alternative future trajectories of IAS and a basis for the future quantification of the effects of biological invasions on biodiversity, human livelihoods and well being. Having identified the primary importance of variables related to public 
environmental awareness and technological and trade development as key determinant of biological invasions will also help to shape how to address future policy and management needs that are required to mitigate the impact of this major driver of biodiversity loss.

Supplementary Information The online version contains supplementary material available at https://doi.org/10.1007/s11625-021-00963-6.

Acknowledgements This research was funded through the COST Action "Alien Challenge" [Grant number TD1209]; the 2017-2018 Belmont Forum and BiodivERsA joint call for research proposals, under the BiodivScen ERA-Net COFUND programme, and with the funding organisations AEI, FWF and BMBF [grant numbers AEI PCI2018-092966 (NRP)/FWF project 4011-B32 (FE, SD, GL, BeL)/ BMBF projects 01LC1807A (HS) and 01LC1807B (JMJ)]; Deutsche Forschungsgemeinschaft [grant numbers InDyNet, JE 288/8-1; JE 288/9-1, 9-2 (JMJ)/via iDiv FZT 118, 202548816 (MW)]; OP RDE grant EVA4.0 [grant number CZ.02.1.01/0.0/0.0/16_019/0000803] (AML); CONICYT [grant number AFB170008] (AP); UK-SCAPE programme, Natural Environment Research Council [grant number NE/ R016429/1] (HER). We highly appreciate the constructive comments of three anonymous reviewers and the handling editor, Iris Bohnet. This manuscript is based on the work done by $\mathrm{BvH}$ while serving at the U.S. National Science Foundation, but the views expressed in the paper do not necessarily reflect those of the U.S. National Science Foundation.

Author contributions NR-P: conceptualization, methodology, formal analysis, investigation, writing-original draft, writing-review and editing, visualization, project administration. FE, BrL, WR: conceptualization, methodology, investigation, writing-original draft, writing-review and editing. LR, JV: investigation, methodology, writing-review and editing. HER: investigation-workshop and online contribution, writing - review and editing, funding acquisition. SB, SD, K-HE, JMJ, SK, IK, BeL, AML, MO, AP, GDP, HS, MW: investigation - workshop and online contribution, writing - review and editing. MAB, PG, PEH, RPK, MAM, GMR, RS, MRS, BH: investigation-online contribution, writing-review and editing. GL: software, formal analysis, writing_-review and editing.

Open Access This article is licensed under a Creative Commons Attribution 4.0 International License, which permits use, sharing, adaptation, distribution and reproduction in any medium or format, as long as you give appropriate credit to the original author(s) and the source, provide a link to the Creative Commons licence, and indicate if changes were made. The images or other third party material in this article are included in the article's Creative Commons licence, unless indicated otherwise in a credit line to the material. If material is not included in the article's Creative Commons licence and your intended use is not permitted by statutory regulation or exceeds the permitted use, you will need to obtain permission directly from the copyright holder. To view a copy of this licence, visit http://creativecommons.org/licenses/by/4.0/.

\section{References}

Alexandratos N, Bruinsma J (2012) World agriculture towards 2030/2050: the 2012 revision. ESA Working paper No. 12-03. FAO, Rome
Calvin K, Bond-Lamberty B, Clarke L, Edmonds J, Eom J, Hartin C, Kim S, Kyle P, Link R, Moss R, McJeon H, Patel P, Smith S, Waldhoff S, Wise M (2017) The SSP4: a world of deepening inequality. Global Environ Change 42:284-296. https://doi.org/ 10.1016/j.gloenvcha.2016.06.010

Carpenter SR, Pingali PL, Bennett EM, Zurek MB (2005) Ecosystems and human well-being: scenarios. Findings of the scenarios working group of the Millennium Ecosystem Assessment. Island Press, Washington

CBD (2010) Strategic plan for biodiversity 2011-2020 and the Aichi targets, conference of the parties to the convention on biological diversity. Secretariat of the Convention on Biological Diversity, Nagoya

CCAFS (2014) Exploring the future(s) of South East Asia: four scenarios for agriculture and food security, livelihoods and environments. CGIAR Research Program on Climate Change, Agriculture and Food Security (CCAFS), Copenhagen

Chytrý M, Wild J, Pyšek P, Jarošik V, Dendoncker N, Reginster I, Pino J, Maskell LC, Vilà M, Pergl J, Kühn I, Spangenberg JH, Settele J (2012) Projecting trends in plant invasions in Europe under different scenarios of future land-use change. Global Ecol Biogeogr 21:75-87. https://doi.org/10.1111/j.1466-8238.2010. 00573.x

Dellink R, Chateau J, Lanzi E, Magné B (2017) Long-term economic growth projections in the shared socioeconomic pathways. Global Environ Change 42:200-214. https://doi.org/10.1016/j.gloenvcha. 2015.06.004

Diagne C, Leroy B, Gozlan RE, Vaissière AC, Assailly C, Nuninger L, Roiz D, Jourdain F, Jarić I, Courchamp F (2020) InvaCost, a public database of the economic costs of biological invasions worldwide. Sci Data 7:277. https://doi.org/10.1038/s41597-020-00586-z

Early R, Bradley BA, Dukes JS, Lawler JJ, Olden JD, Blumenthal DM, Gonzalez P, Grosholz ED, Ibañez I, Miller LP, Sorte CJB, Tatem AJ (2015) Global threats from invasive alien species in the twenty-first century and national response capacities. Nat Commun 7:12485. https://doi.org/10.1038/ncomms 12485

Essl F, Lenzner B, Bacher S, Bailey S, Capinha C, Daehler C, Dullinger S, Genovesi P, Hui C, Hulme PE, Jeschke JM, Katsanevakis S, Kühn I, Leung B, Liebhold A, Liu CL, MacIsaac HJ, Meyerson LA, Nunez MA, Pauchard A, Pyšek P, Rabitsch W, Richardson DM, Roy HE, Ruiz GM, Russell JC, Sanders NJ, Sax DF, Scalera R, Seebens H, Springborn M, Turbelin A, van Kleunen M, von Holle B, Winter M, Zenni RD, Mattsson BJ, Roura-Pascual N (2020) Drivers of future alien species impacts: an expert-based assessment. Global Change Biol 26:4880-4893. https://doi.org/ 10.1111/gcb.15199

Fujimori S, Hasegawa T, Masui T, Takahashi K, Herran DS, Dai HC, Hijioka Y, Kainuma M (2017) SSP3: AIM implementation of shared socioeconomic pathways. Global Environ Change 42:268283. https://doi.org/10.1016/j.gloenvcha.2016.06.009

Gallopin G, Hammond A, Raskin P, Swart R (1997) Branch points: global scenarios and human choice-a resource paper of the global scenario group. Stockholm Environment Institute, Stockholm

Hulme PE (2017) Climate change and biological invasions: evidence, expectations, and response options. Biol Rev 92:1297-1313. https://doi.org/10.1111/brv.12282

IPBES (2019) Global assessment report on biodiversity and ecosystem services of the Intergovernmental Science-Policy Platform on Biodiversity and Ecosystem Services. Brondizio ES, Settele J, Díaz S, Ngo HT (eds). Secretariat of the Intergovernmental Science-Policy Platform on Biodiversity and Ecosystem Services, Bonn

IPCC (2000) Special report on emissions scenarios. Cambridge University Press, Cambridge 
IPCC (2013) Climate change 2013: The physical science basis. Stocker TF, Qin D, Plattner GK, et al. (eds). Intergovernmental Panel on Climate Change, Cambridge

Jiang LW, O'Neill BC (2017) Global urbanization projections for the shared socioeconomic pathways. Global Environ Change 42:193199. https://doi.org/10.1016/j.gloenvcha.2015.03.008

Kriegler E, Bauer N, Popp A, Humpenöder F, Leimbach M, Strefler J, Baumstark L, Bodirsky BL, Hilaire J, Klein D, Mouratiadou I, Weindl I, Bertram C, Dietrich JP, Luderer G, Pehl M, Pietzcker R, Piontek F, Lotze-Campen H, Biewald A, Bonsch M, Giannousakis A, Kreidenweis U, Müller C, Rolinski S, Schultes A, Schwanitz J, Stevanovic M, Calvin K, Emmerling J, Fujimori S, Edenhofer O (2017) Fossil-fueled development (SSP5): an energy and resource intensive scenario for the 21st century. Global Environ Change 42:297-315. https://doi.org/10.1016/j.gloenvcha.2016.05.015

Kueffer C (2017) Plant invasions in the anthropocene. Science 358:724-725. https://doi.org/10.1126/science.aao6371

Le Maitre DC, Richardson DM, Chapman RA (2004) Alien plant invasions in South Africa: driving forces and the human dimension. S Afr J Sci 100:103-112. https://hdl.handle.net/10520/EJC96204

Lenzner B, Leclère D, Franklin O, Seebens H, Roura-Pascual N, Obersteiner M, Dullinger S, Essl F (2019) A framework for global twenty-first century scenarios and models of biological invasions. Bioscience 69:697-710. https://doi.org/10.1093/biosci/biz070

Lord S, Helfgott A, Vervoort JM (2016) Choosing diverse sets of plausible scenarios in multidimensional exploratory futures techniques. Futures 77:11-27. https://doi.org/10.1016/j.futures.2015. 12.003

Lotz A, Allen CR (2013) Social-ecological predictors of global invasions and extinctions. Ecol Soc 18:15. https://doi.org/10.5751/ es-05550-180315

Mora $\mathrm{O}$, Lattre-Gasquet $\mathrm{M}$, Donnars $\mathrm{C}$, Réchauchère $\mathrm{O}$, Le Mouël C, Dumas P, Moreau C, Brunelle T, Barzman M, Marty P (2016) Agrimonde-Terra foresight: scenarios of land use and food security in 2050. Working paper. INRA/CIRAD, Paris

OECD (2009) The bioeconomy to 2030: designing a policy agenda. Organisation for Economic Co-operation and Development, Paris

O’Neill BC, Tebaldi C, van Vuuren DP, Eyring V, Friedlingstein P, Hurtt G, Knutti R, Kriegler E, Lamarque JF, Lowe J, Meehl GA, Moss R, Riahi K, Sanderson BM (2016) The Scenario Model Intercomparison Project (ScenarioMIP) for CMIP6. Geosci Model Dev 9:3461-3482. https://doi.org/10.5194/gmd-9-3461-2016

O’Neill BC, Kriegler E, Ebi KL, Kemp-Benedict E, Riahi K, Rothman DS, van Ruijven BJ, van Vuuren DP, Birkmann J, Kok K, Levy M, Solecki W (2017) The roads ahead: narratives for shared socioeconomic pathways describing world futures in the 21 st century. Global Environ Change 42:169-180. https://doi.org/10.1016/j. gloenvcha.2015.01.004

Oteros-Rozas E, Martín-López B, Daw TM, Bohensky EL, Butler JRA, Hill R, Martin-Ortega J, Quinlan A, Ravera F, Ruiz-Mallén I, Thyresson M, Mistry J, Palomo I, Peterson GD, Plieninger T, Waylen KA, Beach DM, Bohnet IC, Hamann M, Hanspach J, Hubacek K, Lavorel S, Vilardy SP (2015) Participatory scenario planning in place-based social-ecological research: insights and experiences from 23 case studies. Ecol Soc 20:32. https://doi.org/ 10.5751/es-07985-200432

Palazzo A, Rutting L, Zougmoré R, Vervoort JM, Havlik P, Jalloh A, Aubee E, Helfgott AES, Mason D'Croz D, Islam S, Valin H, Ericksen PJ, Segda Z, Moussa AS, Bayala J, Kadi Kadi HA, Sibiry Traoré PC, Thornton PK (2016) The future of food security, environments and livelihoods in Western Africa: four socio-economic scenarios. Working Paper no. 130. CGIAR Research Program on Climate Change, Agriculture and Food Security, Copenhagen

Pereira LM, Davies KK, den Belder E, Ferrier F, Karlsson-Vinkhuyzen S, Kim H, Kuiper JJ, Okayasu S, Palomo MG, Pereira HM, Peterson G, Sathyapalan J, Schoolenberg M, Alkemade R, Carvalho
Ribeiro S, Greenaway A, Hauck J, King N, Lazarova T, Ravera F, Chettri N, Cheung WWL, Hendriks RJJ, Kolomytsev G, Leadley P, Metzger J-P, Ninan KN, Pichs R, Popp A, Rondinini C, Rosa I, van Vuuren D, Lundquist CJ (2020) Developing multiscale and integrative nature-people scenarios using the nature futures framework. People Nat 2:1172-1195. https://doi.org/10. 1002/pan3.10146

Peterson GD, Cumming GS, Carpenter SR (2003) Scenario planning: a tool for conservation in an uncertain world. Conserv Biol 17:358-366

Pyšek P, Hulme PE, Simberloff D, Bacher S, Blackburn TM, Carlton JT, Dawson W, Essl F, Foxcroft LC, Genovesi P, Jeschke JM, Kühn I, Liebhold AM, Mandrak NE, Meyerson LA, Pauchard A, Pergl J, Roy HE, Seebens H, van Kleunen M, Vilà M, Wingfield MJ, Richardson DM (2020) Scientists' warning on invasive alien species. Biol Rev 95:1511-1534. https://doi.org/10.1111/ brv. 12627

R Core Team (2020) R: a language and environment for statistical computing. R Foundation for Statistical Computing, Vienna. https:// www.R-project.org

Riahi K, van Vuuren DP, Kriegler E, Edmonds J, O’Neill BC, Fujimori S, Bauer N, Calvin K, Dellink R, Fricko O, Lutz W, Popp A, Cuaresma JC, Samir KC, Leimbach M, Jiang LW, Kram T, Rao S, Emmerling J, Ebi K, Hasegawa T, Havlik P, Humpenoder F, da Silva LA, Smith S, Stehfest E, Bosetti V, Eom J, Gernaat D, Masui T, Rogelj J, Strefler J, Drouet L, Krey V, Luderer G, Harmsen M, Takahashi K, Baumstark L, Doelman JC, Kainuma M, Klimont Z, Marangoni G, Lotze-Campen H, Obersteiner M, Tabeau A, Tavoni M (2017) The shared socioeconomic pathways and their energy, land use, and greenhouse gas emissions implications: an overview. Global Environ Change 42:153-168. https://doi.org/10. 1016/j.gloenvcha.2016.05.009

Ricciardi A, Blackburn TM, Carlton JT, Dick JTA, Hulme PE, Iacarella JC, Jeschke JM, Liebhold AM, Lockwood JL, Maclsaac HJ, Pyšek P, Richardson DM, Ruiz GM, Simberloff D, Sutherland WJ, Wardle DA, Aldridge DC (2017) Invasion science: a horizon scan of emerging challenges and opportunities. Trends Ecol Evol 32:464-474. https://doi.org/10.1016/j.tree.2017.03.007

Rockefeller Foundation, GBN (2010) Scenarios for the future of technology and international development. The Rockefeller Foundation and Global Business Network

Roura-Pascual N, Richardson DM, Chapman RA, Hichert T, Krug RM (2011) Managing biological invasions: charting courses to desirable futures in the Cape Floristic Region. Reg Environ Change 11:311-320. https://doi.org/10.1007/s10113-010-0133-5

Roy HE, Peyton JM, Booy O (2020) Guiding principles for utilizing social influence within expert-elicitation to inform conservation decision-making. Global Change Biol 26:3181-3184. https://doi. org/10.1111/gcb.15062

Sala OE, Chapin FSI, Armesto JJ, Berlow E, Bloomfiels J, Dirzo R, Huber-Sanwald E, Huenneke LF, Jackson RB, Kinzig A, Leemans R, Lodge DM, Mooney H, Oesterheld M, Poff NL, Sykes MT, Walker BH, Walker M, Wall D (2000) Global biodiversity scenarios for the year 2100. Science 287:1770-1774. https://doi. org/10.1126/science.287.5459.1770

Saldaña J (2013) The coding manual for qualitative researchers. SAGE Publications, London

Sardain A, Sardain E, Leung B (2019) Global forecasts of shipping traffic and biological invasions to 2050. Nat Sustain 2:274-282. https://doi.org/10.1038/s41893-019-0245-y

Seebens H, Blackburn TM, Dyer EE, Genovesi P, Hulme PE, Jeschke JM, Pagad S, Pyšek P, Winter M, Arianoutsou M, Bacher S, Blasius B, Brundu G, Capinha C, Celesti-Grapow L, Dawson W, Dullinger S, Fuentes N, Jäger H, Kartesz J, Kenis M, Kreft H, Kühn I, Lenzner B, Liebhold A, Mosena A, Moser D, Nishino M, Pearman D, Pergl J, Rabitsch W, Rojas-Sandoval J, Roques A, 
Rorke S, Rossinelli S, Roy HE, Scalera R, Schindler S, ŠtajerováK T-G, van Kleunen M, Walker K, Weigelt P, Yamanaka T, Essl F (2017) No saturation in the accumulation of alien species worldwide. Nat Commun 8:14435. https://doi.org/10.1038/ncomm s14435

Simberloff D, Martin JL, Genovesi P, Maris V, Wardle DA, Aronson J, Courchamp F, Galil B, García-Berthou E, Pascal M, Pyšek P, Sousa R, Tabacchi E, Vilà M (2013) Impacts of biological invasions: what's what and the way forward. Trends Ecol Evol 28:5866. https://doi.org/10.1016/j.tree.2012.07.013

Spangenberg JH, Bondeau A, Carter TR, Fronzek S, Jaeger J, Jylhä K, Kühn I, Omann I, Paul A, Reginster I, Rounsevell M, Schweiger O, Stocker A, Sykes MT, Settele J (2012) Scenarios for investigating risks to biodiversity. Global Ecol Biogeogr 21:5-18. https:// doi.org/10.1111/j.1466-8238.2010.00620.x

Spear D, Foxcroft LC, Bezuidenhout H, McGeoch MA (2013) Human population density explains alien species richness in protected areas. Biol Conserv 159:137-147. https://doi.org/10.1016/j.biocon.2012.11.022

Stoett P, Roy HE, Pauchard A (2019) Invasive alien species and planetary and global health policy. Lancet Planet Health 3:e400-e401. https://doi.org/10.1016/S2542-5196(19)30194-9

van der Heijden K (2005) Scenarios: the art of strategic conversation. Wiley, Chichester

van der Mensbrugghe D (2015) Shared socio-economic pathways and global income distribution. Center for Global Trade Analysis

van Vuuren DP, Kriegler E, O'Neill BC, Ebi KL, Riahi K, Carter TR, Edmonds J, Hallegatte S, Kram T, Mathur R, Winkler H (2014) A new scenario framework for climate change research: scenario matrix architecture. Clim Change 122:373-386. https://doi.org/ 10.1007/s10584-013-0906-1

van Vuuren DP, Stehfest E, Gernaat D, Doelman JC, van den Berg M, Harmsen M, de Boer HS, Bouwman LF, Daioglou V, Edelenbosch OY, Girod B, Kram T, Lassaletta L, Lucas PL, van Meijl H, Müller C, van Ruijven BJ, van der Sluis S, Tabeau A (2017) Energy, land-use and greenhouse gas emissions trajectories under a green growth paradigm. Global Environ Change 42:237-250. https:// doi.org/10.1016/j.gloenvcha.2016.05.008

Vaz AS, Kueffer C, Kull CA, Richardson DM, Schindler S, MuñozPajares AJ, Vicente JR, Martins J, Hui C, Kühn I, Honrado JP (2017) The progress of interdisciplinarity in invasion science. Ambio 46:428-442. https://doi.org/10.1007/s13280-017-0897-7

Vervoort JM, Palazzo A, Mason-D’Croz D, Ericksen PJ, Thornton PK, Kristjanson P, Förch W, Herrero M, Havlik P, Jost C, Rowlands $\mathrm{H}$ (2013) The future of food security, environments and livelihoods in Eastern Africa: four socio-economic scenarios. CGIAR Research Program on Climate Change Agriculture and Food Security, Copenhagen

Vervoort JM, Bendor R, Kelliher A, Strik O, Helfgott AER (2015) Scenarios and the art of worldmaking. Futures 74:62-70. https:// doi.org/10.1016/j.futures.2015.08.009

Vervoort JM, Helfgott A, Moragues-Faus A, Lord S, Avermaete T (2016) Explorative EU scenarios. TRANSMANGO: EU KBBE.2013.2.5-01. Assessment of the impact of global drivers of change on Europe's food and nutrition securit (FNS). Grant agreement no: 613532

Wilson JRU, Faulkner KT, Rahlao SJ, Richardson DM, Zengeya TA, van Wilgen BW (2018) Indicators for monitoring biological invasions at a national level. J Appl Ecol 55:2612-2620. https://doi. org/10.1111/1365-2664.13251

Wilson JRU, Measey J, Richardson DM, van Wilgen BW, Zengeya TA (2020) Potential futures of biological invasions in South Africa. In: van Wilgen BW, Measey J, Richardson DM, Wilson JR, Zengeya TA (eds) biological invasions in South Africa. Springer, Cham, pp 917-946. https://doi.org/10.1007/978-3-030-32394-3_ 31

Publisher's Note Springer Nature remains neutral with regard to jurisdictional claims in published maps and institutional affiliations.

\section{Authors and Affiliations}

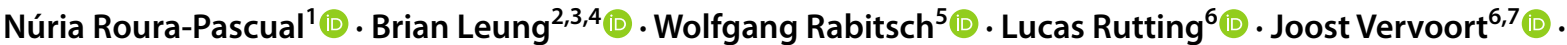

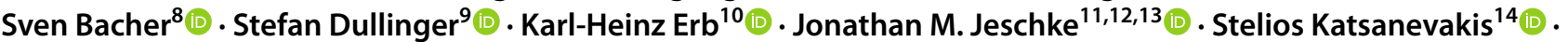

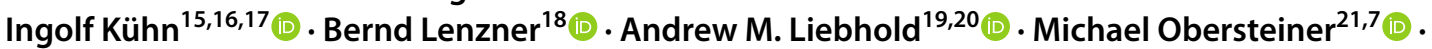

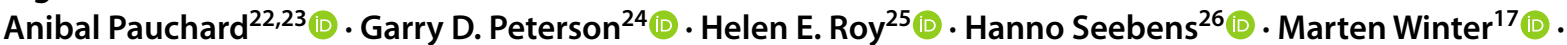

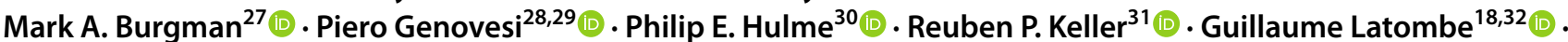

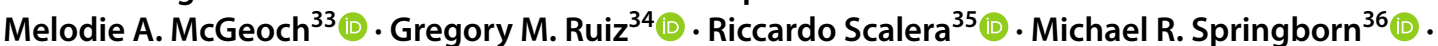 Betsy von Holle ${ }^{37}$ (i) Franz EssI ${ }^{18,38}$ (i)}

1 Departament de Ciències Ambientals, Facultat de Ciències, Universitat de Girona, 17003 Girona, Catalonia, Spain

2 Department of Biology, McGill University, Montreal, QC H3A 1B1, Canada

3 Bieler School of Environment, McGill University, Montreal, QC H3A 2A7, Canada

4 Smithsonian Tropical Research Institute, PO Box 0843-03092, Panama City, Panama

5 Environment Agency Austria, Vienna, Austria

6 Copernicus Institute of Sustainable Development, University of Utrecht, Princetonlaan 8a, 3584 CB Utrecht, The Netherlands
7 University of Oxford, Environmental Change Institute, South Parks Rd, Oxford OX1 3QY, UK

8 University of Fribourg, Fribourg, Switzerland

9 Department of Botany and Biodiversity Research, University of Vienna, Rennweg 14, 1030 Vienna, Austria

10 Institute of Social Ecology, University of Natural Resources and Life Sciences Vienna, Schottenfeldgasse 29, 1070 Vienna, Austria

11 Department of Biology, Chemistry, Pharmacy, Institute of Biology, Freie Universität Berlin, Königin-Luise-Str. 1-3, 14195 Berlin, Germany 
12 Leibniz Institute of Freshwater Ecology and Inland Fisheries (IGB), Müggelseedamm 310, 12587 Berlin, Germany

13 Berlin-Brandenburg Institute of Advanced Biodiversity Research (BBIB), Königin-Luise-Str. 2-4, 14195 Berlin, Germany

14 Department of Marine Sciences, University of the Aegean, 81100 Mytilene, Greece

15 Helmholtz Centre for Environmental Research-UFZ, Theodor-Lieser Str. 4, 06120 Halle, Germany

16 Institute of Biology/Geobotany and Botanic Garden, Martin Luther University Halle-Wittenberg, Große Steinstraße 79/80, 06108 Halle, Germany

17 German Centre for Integrative Biodiversity Research (iDiv) Halle-Jena-Leipzig, Puschstr. 4, 04103 Leipzig, Germany

18 Bioinvasions, Global Change, Macroecology Group, Department of Botany and Biodiversity Research, University of Vienna, Rennweg 14, 1030 Vienna, Austria

19 US Forest Service Northern Research Station, Morgantown, WV 26505, USA

20 Faculty of Forestry and Wood Sciences, Czech University of Life Sciences Prague, 16521 Praha 6-Suchdol, CZ, Czech Republic

21 International Institute of Applied Systems Analysis (IIASA), Schlosspl 1, A-2361 Laxenburg, Austria

22 Facultad de Ciencias Forestales, Universidad de Concepción, LIB, 4070386 Concepcion, Chile

23 Instituto de Ecología Y Biodiversidad (IEB), 7800003 Santiago, Chile

24 Stockholm Resilience Centre, Stockholm University, Kräftriket 2B, 10691 Stockholm, Sweden
25 UK Centre for Ecology and Hydrology, Benson Lane, Wallingford OX10 8BB, UK

26 Senckenberg Biodiversity and Climate Research Centre (SBiK-F), Senckenberganlage 25, 60325 Frankfurt am Main, Germany

27 Centre for Environmental Policy, Imperial College London, London SW7 1NE, England

28 Institute for Environmental Protection and Research (ISPRA), Rome, Italy

29 Chair IUCN/SSC Invasive Species Specialist Group, Rome, Italy

30 Bio-Protection Research Centre, Lincoln University, Lincoln, Canterbury 7648, New Zealand

31 School of Environmental Sustainability, Loyola University Chicago, 1032 W. Sheridan Rd., Chicago, IL 60660, USA

32 Institute of Evolutionary Biology, The University of Edinburgh, King's Buildings, Edinburgh EH9 3FL, UK

33 Department of Ecology, Evolution and Environment, La Trobe University, Melbourne, VIC 3086, Australia

34 Smithsonian Environmental Research Center, POB 28, Edgewater, MD 21037, USA

35 IUCN/SSC Invasive Species Specialist Group, Rome, Italy

36 Department of Environmental Science and Policy, University of CA, Davis, 1 Shields Ave, Davis, CA 95616, USA

37 Division of Environmental Biology, National Science Foundation, Alexandria, VA, USA

38 Centre for Invasion Biology, Department of Botany and Zoology, Stellenbosch University, Stellenbosch, South Africa 